\title{
The decision of technological equipment for large dimension frameworks lifting
}

\author{
Anatoly Gerasimov ${ }^{1,}{ }^{*}$, Elena Koltsova ${ }^{1}$, Alexander Markov ${ }^{1}$ and Ivan Zlobin ${ }^{1}$ \\ ${ }^{1}$ Moscow State University of Civil Engineering, 26, Yaroslavskoe Shosse, Moscow, Russia
}

\begin{abstract}
This publication has recommendation for choosing and applying the technological infrastructure equipment, which can improve the method of large dimension frameworks lifting in buildings and constructions erection. As experimental researches and construction practice showed while increasing the ceiling panel thickness till 350-450 $\mathrm{mm}$ the adhesion force is enhanced and can reach $50-70 \%$ by ceiling panel mass. In that context the necessity to develop the method of adhesion force determination and find technological equipment for decreasing this force is appeared purposely for enhancing the operational efficiency of load weight-lifting equipment. The experimental researches were occurred for purpose to find out the dependence of adhesion force off amount of factors. The analytic expression, allowing calculating adhesion force, was derived after mathematical elaboration of results.
\end{abstract}

\section{Introduction}

Nowadays the method of large dimension frameworks elevation is widespread used [1, 2, 3]. As such amounts of questions are appeared, which are connected with specific particularities of buildings erection technology applying this method $[4,5]$.

This publication has recommendation for choosing and applying the technological infrastructure equipment, which can improve the method of large dimension frameworks lifting in buildings and constructions erection.

During multistory building construction the reinforced concrete panels are manufactured one above the other in a packet without formwork bottom usage. The release layer is coated to the underlying panel to decrease the adhesion between the panels $[6,7]$. Though, nevertheless, the adhesion force can be significant. The effective load weightlifting equipment is increased to over pass the adhesion force. Until quite recently in the necessary elevating capacity of equipment calculating the adhesion force was taken into account by overloading ratio, accepted without basis calculation in 1,2-1,25 units. As experimental researches and construction practice showed while increasing the ceiling panel thickness till $350-450 \mathrm{~mm}$ the adhesion force is enhanced and can reach $50-70 \%$ by ceiling panel mass. In that context the necessity to develop the method of adhesion force determination and find technological equipment for decreasing this force is appeared purposely for enhancing the operational efficiency of load weight-lifting equipment.

\footnotetext{
${ }^{*}$ Corresponding author: GerasimovAI@mgsu.ru
} 
Due to elevation process of ceiling panel their situation is continuously changed, in view of this the building framework can lose stability in the position of rest. According to lifting scheme, including into the working plan, the framework stability should be checked on every stage of building assembling. As panels are lifted in definitive sequence it is always necessary to release the one panels and anchor the other by metal slips during assembling. This work is very responsible and requires constant attention, both the labor and engineers [8]. In construction practice the cases of column stability loses in consequence of structural model changing caused by ceiling panels blocking up [9-11]. All of this led to necessary technological procedures prevented ceiling panels displacement developing.

\section{Methods}

The experimental researches were occurred for purpose to find out the dependence of adhesion force off amount of factors. The analytic expression, allowing calculating adhesion force, was derived after mathematical elaboration of results. Adhesion force is calculated by formula (1):

$$
S_{0}=k(h-4)^{2}+c
$$

$\mathrm{S}_{0}$ - panel adhesion force, $\mathrm{kN}$;

$\mathrm{h}-$ slab thickness, $\mathrm{mm}$;

k и с -empirical constant.

The $\mathrm{k}$ and $\mathrm{c}$ constants are determined by table 1 . The specific adhesion of slab with base, depending on release layer composition, is determined by experimental way. As a result of different release layer compositions usage the following values of specific adhesion were get, $\mathrm{kPa}$ :

- Ethylene lacquer with lime mud - 12.4;

- Casein-chalk paste and casein-chalk paste with stand oil additive -13.1;

- Water-repellent silicon fluid - 14.1.

The founded adhesion force value and value of console section adhesion force are summed up in the presence of ceiling slab a console section. The summarized force is calculated by formula (2):

$$
S=1,1\left(S_{0}+\sigma a\right)
$$

$\mathrm{S}$ - summarized adhesion force, $\mathrm{kN}$;

$\sigma-$ specific adhesion, $\mathrm{kPa}$;

$\mathrm{a}$-console length, $\mathrm{mm}$.

Presented dependencies in table 1 allow to find the adhesive force of $1 \mathrm{~m}$ width field. To find the whole adhesion force per one elevator the determined adhesion value should be multiplied by load area width in meters, per this elevator. To determine the whole load per one elevator the determined adhesion force value should be summarized with its own panel mass per this elevator.

The usage area of determined dependencies is restricted by the following limits of factors changing:

- Specific adhesion 5,5-43 Pa;

- Panel thickness $40-500 \mathrm{~mm}$;

- Concrete strength $10 \ldots 30 \mathrm{MPa}$.

The dependence of ceiling slab degree of rotation on shape and dimensions of stiffening core, express in terms of permissible liner deflection of the outermost column from the 
center allows to determine the limiting number value between the stiffening core and ceiling slab.

Table 1. The k and c coefficient value.

\begin{tabular}{|c|c|c|c|c|}
\hline \multirow{2}{*}{$\begin{array}{c}\text { Specific } \\
\text { adhesion, kPa }\end{array}$} & \multirow{2}{*}{$\mathrm{k}$} & \multicolumn{3}{|c|}{$\mathrm{c}$} \\
\cline { 3 - 5 } & & 10 & 20 & 30 \\
\hline & & \multicolumn{3}{|c|}{ Concrete strength, MPa } \\
\hline 6 & 0,0028 & 0,17 & 0,22 & 0,28 \\
\hline 8 & 0,0027 & 0,25 & 0,31 & 0,38 \\
\hline 10 & 0,0047 & 0,33 & 0,4 & 0,48 \\
\hline 12 & 0,0056 & 0,41 & 0,49 & 0,58 \\
\hline 14 & 0,0067 & 0,49 & 0,49 & 0,67 \\
\hline 16 & 0,0077 & 0,57 & 057 & 0,77 \\
\hline 18 & 0,0086 & 0,65 & 0,65 & 0,87 \\
\hline 20 & 0,0094 & 0,74 & 0,74 & 0,96 \\
\hline
\end{tabular}

The number value is calculated by formula (3):

$$
a \leq r\left\{\cos \left[\frac{\pi}{n}-\arcsin \frac{[d] b}{2 R}\right]-\cos \frac{\pi}{n}\right\}
$$

$a$ - gap spacing between ceiling slab and stiffening core, $\mathrm{mm}$;

$r$ - circumscribed-circle stiffening core radius, $\mathrm{mm}$;

$n$ - amount of core planes;

$[d]$ - permissible variation of columns, $\mathrm{mm}$;

$b$ - gap spacing between column and ceiling slab, $\mathrm{mm}$;

$R$ - distance from the stiffening core center to outermost column, $\mathrm{mm}$.

\section{Results and Discussion}

The adhesive force can be too significant during pouring concrete of large dimension panels with huge width and in some cases can exceed lifting ability of elevation equipment. In these cases it is appropriate the application of special equipment for adhesion force decreasing in working plan. There are two types of equipment can be used. The first is dismountable and the second is stationary. The dismountable equipment is used in buildings erecting with help of lift slab method, when all slabs are manufactured in packet (one above the other) and then lifted. The stationary equipment usage simplify uplift of large sized fabrics, for example, solid-cast stories, which are pouring concrete one by one on the ground level and then straight lifted, absolving the equipment for concrete pouring of the next storey.

The dismountable equipment for uplift simplifying is represented two carrying elements, connected by two pressure adjusting screws or worm-and-worm gears (figure 1). While pouring concrete of ceiling panels the core drivers are installed into, which ones provide chase development in panels. It is recommended to make the chases on the upper surface of each panel in order to simplifying their further attachment. Progressively ceiling panel elevation in the chase of successive panel the equipment is installed and the pressure adjusting screws are drawn up till required effort. The rafter tie is occurred by torque spanner. By the end of installing and drawing up of whole appliance the elevation equipment is turned on in usual mode and the ceiling panel is uplifted, while appliance are deinstalled and prepared for installation for the successive slab.

The stationary appliance is represented a flexible metal bottom, anchored to concrete blinding coat with adjustable length metal stay braces encased in (figure 2). The platform consists of bearing bar elements and metal sheet. While uplifting of lifting product the 
platform due to adhesion force begin to lift jointly to product. Taking into account the fact that the length of stay braces increases from edge to center during lifting process the platform is sagged and the product uplift easily, after which it turns into the departure horizontal position due to elasticity of bearing elements.

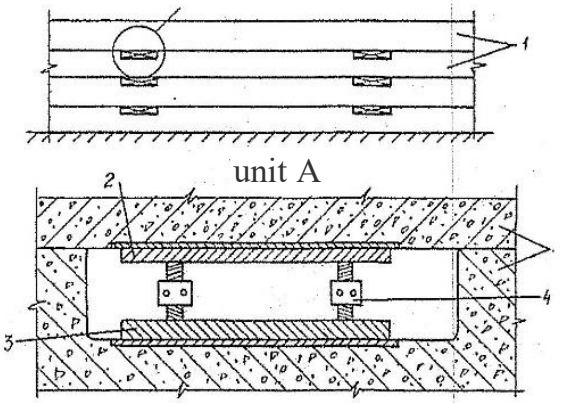

Fig. 1. The stationary appliance - sag platform, where: 1 - ceiling slab; 2 - overhead support rod; 3 - underneath support rod; 4 pressure adjusting screws.

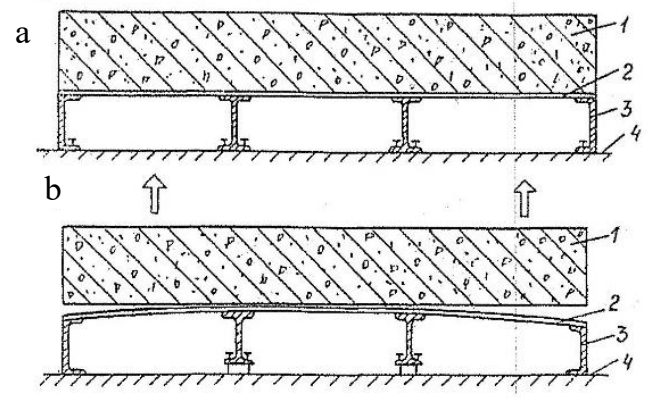

Fig. 2. The dismountable appliance for simplify panel uplift, where: a - during fabric manufacturing process; $b$ - at the beginning of fabric elevation, 1 reinforced concrete unit; 2 - metal sheet; 3 bearing elements; 4 - base.

In buildings, which have two or more stiffening cores the displacement of any ceiling slab horizontally is restricted by space gap between ceiling slab and stiffening core, it means no more than 100-250 mm.

In punctiform buildings with one stiffening core the slab swing around the stiffening core is possible. The stiffening cores are made polyangular for limitation of degree rotation.

The panel quantity stiffening core increasing leads to enhancing possible angle degree rotation around the core. That's why the preference during selection procedure of spaceplanning decision in equal conditions should be given to tetragonal stiffening core, which one configuration provides the most rational floor plan and safety of ceiling slab lifting.

The core dimension should be as biggest as possible, because the dimension increasing essential enhances the rigidity cross-section, what allow:a o reduce walls thickness and decreasing the percent of reinforcing, in other words it leads to construction materials economy.

The special appliances are used for restricting the angle degree ratio in cases when the real number value of the space gap extends limit value, calculated by formula (3). The restrictive appliance presented as buffer stop consist of screw spindle with roller framed in box housing section and flat clamp for anchoring the buffer stop to ceiling slab (figure 3 ).

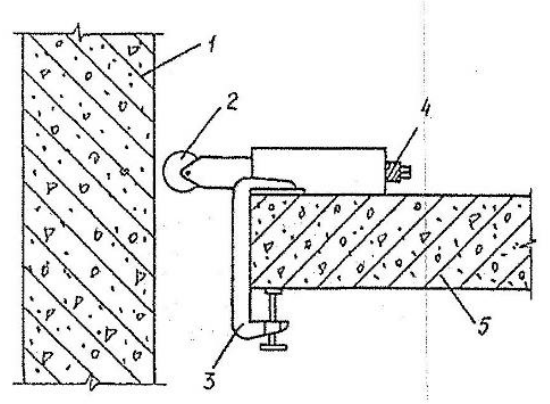

Fig. 3. The buffer stop for restricting the angle degree ratio, where: 1 - plane of stiffening core; 2 roller; 3 - flat clamp; 4 - screw spindle; 5 - ceiling slab. 
The electromechanical lifting equipment with self-contained engine is used for buildings and construction erection by elevation method. Such equipment shows high operational dependability during buildings and construction erection in the most severe climatic conditions.

The elevating equipment $7221 \mathrm{M}$ is designed for installation in circumference of column during building erection by stories and slabs lifting method. The elevators have split frame, electrical engine, individual reducing gear train, pinion drive of clenching bolts mechanism.

Compared to model $7221 \mathrm{M}$ elevators are supplied $30-75 \mathrm{~B}$ reducing gear train, overtime clutch on clenching bolts mechanism and chain wheel gear mechanism clenching.

The elevators $25-77 / 100$ are intended for installation column in circumference till $600 \times 1600 \mathrm{~mm}$ while lifting heavy constructions.

The elevating equipment model $28-78 / 50$ is supplied for construction elevating alongside the stiffening cores.

Table 2. Technique features of electromechanical lifting equipment with self-contained engine.

\begin{tabular}{|c|c|c|c|c|}
\hline \multirow[b]{2}{*}{ Characteristics } & \multicolumn{4}{|c|}{ Model } \\
\hline & $7221 \mathrm{M}^{*}$ & $30-73 Б^{* *}$ & $\begin{array}{c}25- \\
77 / 100 * *\end{array}$ & $28-78 / 50 * *$ \\
\hline 1 & 2 & 3 & 4 & 5 \\
\hline Elevating capacity, $\mathrm{t}$ & 50 & 50 & 100 & 50 \\
\hline $\begin{array}{l}\text { Rate of lifting-descending, } \\
\mathrm{m} / \mathrm{h}\end{array}$ & $2 ; 4$ & 2 & 2 & 3 \\
\hline Installed capacity, $\mathrm{kW}$ & 2,7 & 2,7 & 5,4 & 2,7 \\
\hline $\begin{array}{l}\text { Dimensions, mm: } \\
\text { - Length } \\
\text { - Width } \\
\text { - Height } \\
\text { Elevator mass, } \mathrm{t} \\
\text { Screw amount, pcs. } \\
\text { Screw diameter, mm } \\
\text { Maximum column section } \\
\text { for elevator installation, } \mathrm{m}\end{array}$ & $\begin{array}{c}1440 \\
1225 \\
1150 \\
1,2 \\
2 \\
50 \\
0,45 \times 0,45\end{array}$ & $\begin{array}{c}1745 \\
900 \\
945 \\
0,9 \\
2 \\
50 \\
0,45 \times 0,45\end{array}$ & $\begin{array}{c}2360 \\
1320 \\
1445 \\
1,94 \\
2 \\
75 \\
0,6 \times 0,6\end{array}$ & $\begin{array}{c}1100 \\
910 \\
800 \\
0,59 \\
1 \\
75\end{array}$ \\
\hline Elevator installation scheme & \multicolumn{3}{|c|}{ In circumference of column } & $\begin{array}{l}\text { On the top of } \\
\text { stiffening core }\end{array}$ \\
\hline
\end{tabular}

The equipment complex is added by tools and mechanisms for assembling occurrence represented by:

- Working platform and areas for equipment installation on the head of stiffening core;

- Vertical rack for assembling and deinstalling of lifting stay brace;

- Chain winch for lifting or lowering lifting stay brace.

\section{Conclusions}

Technical-and-economic efficiency of appliance for simplifying uplift usage is specified of work load increasing in total load on the elevating equipment. The efficiency during the buildings erection by ceiling slab lifting method with stay braces usage is reached by using the change non inverter irregular lewis for inverter regular buffer stops. Due to this the labor intensivity of fastening by wedges is decreased and the duration of operation fulfilling is reduced too. The usage of appliance for equation forces in lifting stay braces is attained by increasing of lifting equipment operational efficiency. 


\section{References}

1. S. Sinenko, A. Ahmetgaliev, A. Slavin, IOP Conference Series: Materials Science and Engineering 365(6), 062039 (2018)

2. P. Oleynik, S. Sinenko, B. Zhadanovsky, V. Brodsky, M. Kuzhin, MATEC Web of Conferences 86 (2016) doi:10.1051/matecconf/20168604059

3. A. Lapidus, T. Bidov, A. Khubaev, MATEC Web of Conferences 117 (2017) doi: 10.1051/matecconf/201711700094

4. A. Lapidus, T. Bidov, A. Khubaev, MATEC Web of Conferences 251 (2017) doi: $10.1051 /$ matecconf $/ 201825105014$

5. H. Su, H. Jing, Q. Yin, L. Yu, Advances in Civil Engineering (2018) doi:10.1155/2018/1326503

6. A. Sigalov, S. Sinenko, T. Poznahirko, MATEC Web of Conferences 117 (2017) doi:10.1051/matecconf $/ 201711700158$

7. S. Sinenko, A. Slavina, MATEC Web of Conferences 106 (2017) doi:10.1051/matecconf/201710608016

8. H. Su, H. Jing, Q. Yin, L. Yu, Advances in Civil Engineering (2018) doi:10.1155/2018/1326503

9. L. Florez, J.C. Cortissoz, Procedia Engineering 164, $42-48$ (2016)

10. O.M. Smirnova, International Journal of Civil Engineering and Technology, 9(8), 1724-1732 (2018)

11. O.M. Smirnova, International Journal of Civil Engineering and Technology, 9(8), 1733-1740 (2018) 